\title{
Altitude exposure in pediatric pulmonary hypertension-are we ready for (flight) recommendations?
}

\author{
Ulrike Herberg^, Ralf Knies, Nicole Müller, Johannes Breuer \\ Department of Pediatric Cardiology, University Hospital Bonn, Bonn, Germany \\ Contributions: (I) Conception and design: U Herberg, J Breuer; (II) Administrative support: U Herberg, J Breuer; (III) Provision of study materials or \\ patients: All authors; (IV) Collection and assembly of data: All authors; (V) Data analysis and interpretation: U Herberg; (VI) Manuscript writing: All \\ authors; (VII) Final approval of manuscript: All authors. \\ Correspondence to: Ulrike Herberg, MD. Department of Pediatric Cardiology, University Hospital Bonn, Eltern-Kind-Zentrum Bonn, Gebd. 30 \\ 4G/108, Venusberg Campus 1, 53127 Bonn, Germany. Email: ulrike.herberg@ukbonn.de.
}

\begin{abstract}
Patients with congenital heart disease are surviving further into adulthood and want to participate in multiple activities. This includes exposure to high altitude by air travel or recreational activities, such as hiking and skiing. However, at an altitude of about 2,500 $\mathrm{m}$, the barometric environmental pressure is reduced and the partial pressure of inspired oxygen drops from $21 \%$ to $15 \%$ (hypobaric hypoxia). In physiologic response to high-altitude-related hypoxia, pulmonary vasoconstriction is induced within minutes of exposure followed by compensatory hyperventilation and increased cardiac output. Even in healthy children and adults, desaturation can be profound and lead to a significant rise in pulmonary pressure and resistance. Individuals with already increased pulmonary pressure may be placed at risk during high-altitude exposure, as compensatory mechanisms may be limited. Little is known about the physiological response and risk of developing clinically relevant events on altitude exposure in pediatric pulmonary hypertension $(\mathrm{PAH})$. Current guidelines are, in the absence of clinical studies, mainly based on expert opinion. Today, healthcare professionals are increasingly faced with the question, how best to assess and advise on the safety of individuals with PAH planning air travel or an excursion to mountain areas. To fill the gap, this article summarises the current clinical knowledge on moderate to high altitude exposure in patients with different forms of pediatric PAH.
\end{abstract}

Keywords: Children; pulmonary hypertension (PAH); high altitude; air travel; Fontan

Submitted May 14, 2020. Accepted for publication Aug 27, 2020.

doi: $10.21037 / \mathrm{cdt}-20-494$

View this article at: http://dx.doi.org/10.21037/cdt-20-494

\section{Introduction}

Nowadays, children and young adults with pulmonary hypertension $(\mathrm{PAH})$ can be treated with a variety of drugs and interventions thus life expectancy is prolonged and quality of life has improved over the last decade. These individuals wish to take part in a normal life, including traveling by airplane and participating in altitude activities. This article discusses the physiology of altitude exposure, the current state of knowledge in children and adults with $\mathrm{PAH}$, and provides a balanced overview of the latest recommendations for safe travel in pediatric $\mathrm{PAH}$.

\section{Cardiopulmonary response to high altitude}

With increasing altitude, barometric pressure, air temperature and air humidity decrease. As a consequence, the inspired oxygen partial pressure and the alveolar oxygen pressure decline in an exponential fashion (1-3) (Figure 1). At sea level, oxygen constitutes $21 \%$ of inspired air, which

\footnotetext{
^ ORCID: 0000-0002-9386-0258.
} 


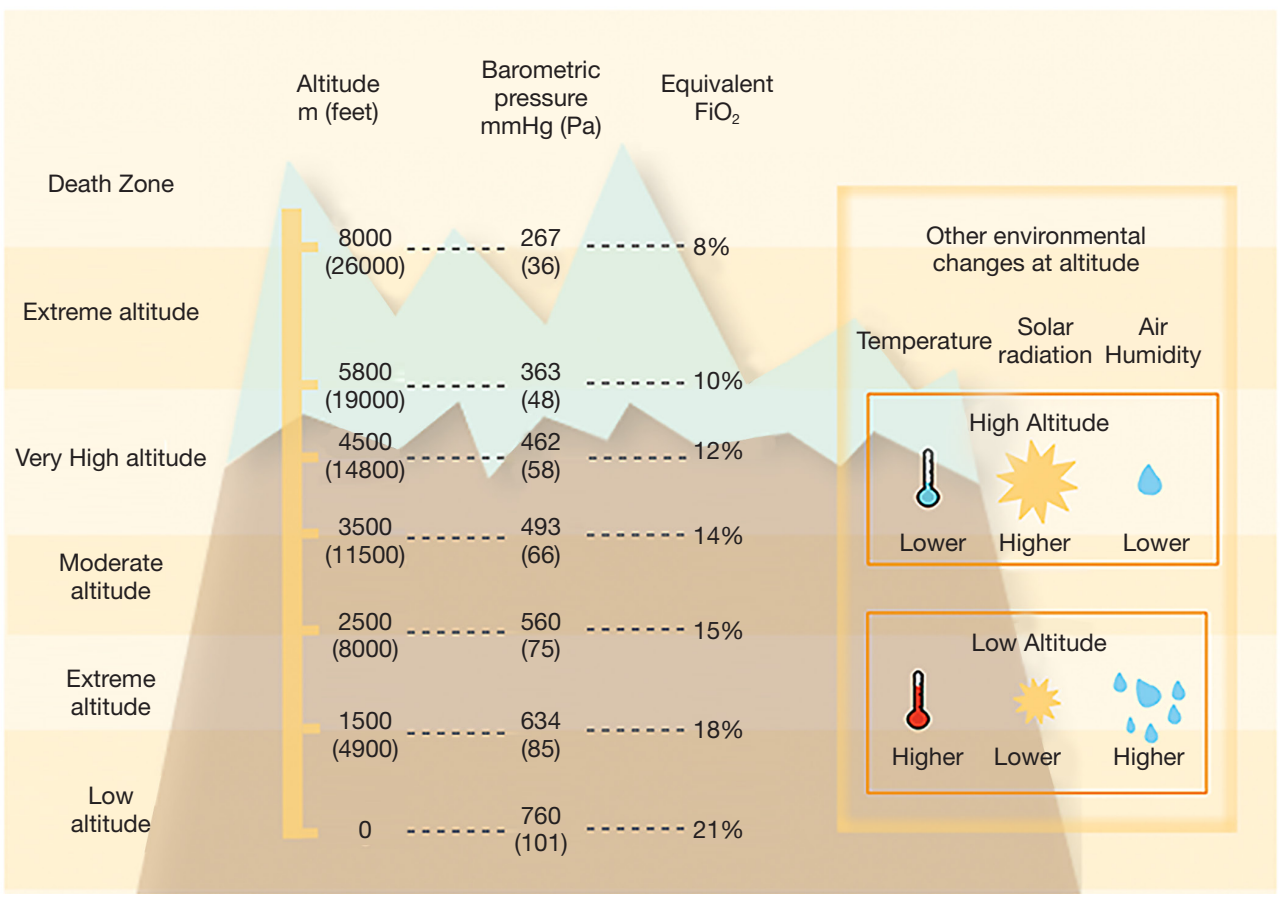

Figure 1 Altitude classification, Parati et al., 2018 (1), corresponding barometric pressure and fraction in inspired oxygen for different simulated altitudes in a laboratory setting, according to the 1976 US standard Atmosphere by NASA.

leads to an alveolar partial oxygen pressure of about $100 \mathrm{mmHg}$ (1). At higher altitude, for example at the height of about 2,438 $\mathrm{m}(8,000 \mathrm{ft})$ above sea level (asl), which is equivalent to the minimal allowed cabin pressure in an aircraft, the same percentage of oxygen in the inspired air, combined with a lower barometric pressure, results in a lower alveolar partial oxygen pressure of about 60 $75 \mathrm{mmHg}$ (4) depending on position and activity. This low alveolar partial oxygen pressure is equivalent to a hypoxic air mixture with a fraction of inspired oxygen of $15.1 \%$ at sea level (1). In a healthy individual, this results in a fall in arterial oxygen tension to $53-64 \mathrm{mmHg}$ with respective oxygen saturations measured by pulse oximetry $\left(\mathrm{SpO}_{2}\right)$ in the range of about $85-91 \%(4,5)$.

Focussing on air or mountain travel, the cardiovascular response at altitudes of between 1,500-2,500 m (up to $3,000 \mathrm{~m}$ asl) is relevant for most individuals. This altitude range includes most ski destinations with overnight stay and the maximal allowed in-flight cabin pressure (Figure 1).

Exposure to acute hypoxia has multiple effects on the cardiovascular and pulmonary systems. A series of physiologic cardiovascular responses are initiated immediately, as well as within hours, followed by cardiopulmonary adaptation within days (Figure 2).

\section{Pulmonary arterial pressure (PAP)}

Alveolar hypoxia and to a lesser degree arterial hypoxemia induces pulmonary vasoconstriction immediately $(1,6,7)$. The individual response to alveolar hypoxia is variable, genetically determined and does increase on exercise (5,8-10).

In the healthy individual, a relevant increase in PAP due to pulmonary vasoconstriction occurs at altitudes of about $1,500-2,000 \mathrm{~m}$ and seems to be biphasic $(7,11)$. The first phase occurs within minutes and a second phase of greater pressure elevation plateaus at 2 hours. The hypoxiamediated increase in PAP is fully expressed within 68 hours and reaches is maximum effects during the first days of high-altitude exposure $(1,2)$; PAP remains elevated throughout altitude exposure and declines only moderately during cardiopulmonary adaptation (8).

In a recent study on 118 healthy children and adolescents, systolic pulmonary pressure (sPAP) estimated by Doppler echocardiography was more than twofold higher at high than at low altitude after a rapid ascent to $3,460 \mathrm{~m}(35 \pm 11$ vs. $16 \pm 3 \mathrm{mmHg})(9)$. The variability of sPAP was wide ranging from $22-52 \mathrm{mmHg}$. At high altitude $(3,450 \mathrm{~m})$, the increase in PAP in children has been reported to be higher than that in adults at day 1 , but returned to 


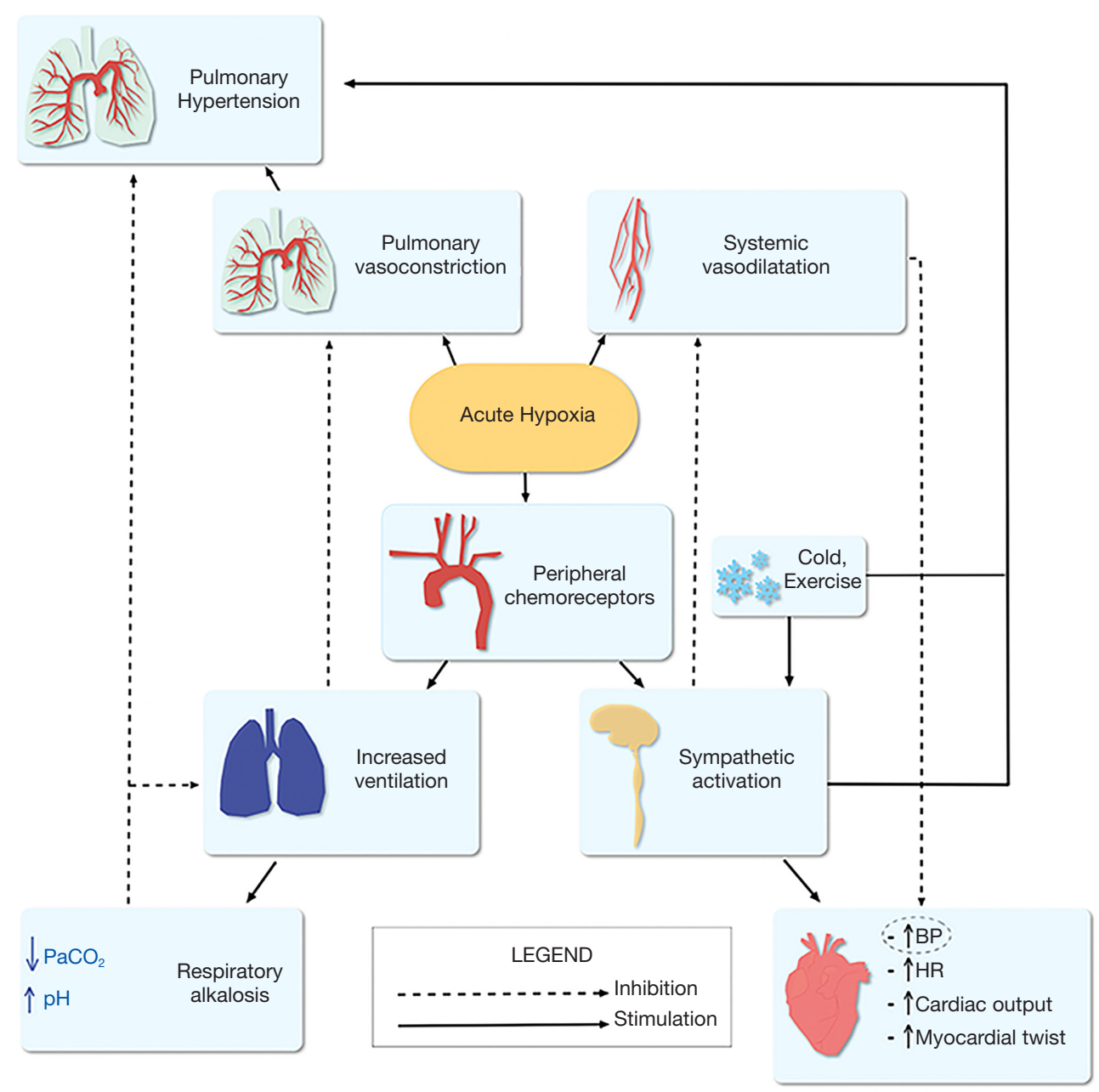

Figure 2 Physiological response to hypoxia, Parati et al., 2018 (1). Life-sustaining oxygen delivery, in spite of a reduction in the partial pressure of inhaled oxygen, is ensured by an increase in pulmonary ventilation, an increase in cardiac output by increasing heart rate, changes in vascular tone, as well as an increase in hemoglobin concentration. BP, blood pressure; $\mathrm{HR}$, heart rate; $\mathrm{PaCO}_{2}, \mathrm{partial}_{\mathrm{Pressure}}$ of arterial carbon dioxide.

adult levels on day 2 (8). Both studies reflect the larger pulmonary vasoreactivity found in children. In adults as well as in children, the rise in PAP correlates closely with altitude (12-16). At moderate altitudes resembling flight conditions, the increase in pulmonary resting pressure in adults is moderate $(20 \%$, increase of sPAP of $6 \mathrm{mmHg}$ on echocardiography) (17).

In response to arterial hypoxia, sympathetic activity is elevated within a few hours, which increases minute ventilation and heart rate, and subsequently cardiac output $(1,12,18-21)$.

\section{Ventilatory response}

Mainly driven by hypoxemia-induced carotid chemoreceptor activation, stimulation of sympathetic activation is followed by a significant increase in minute ventilation (hypoxic ventilatory response). In the healthy, this results in hypocapnia and respiratory alkalosis $(20,22)$. The increase in $\mathrm{pH}$ shifts the oxygen dissociation curve leftwards which means that the $\mathrm{SO}_{2}$ for a given alveolar oxygen pressure also increases (23). Pre-existing lung disease can decrease the efficiency of gas exchange and may limit an individual's ability to increase ventilation and compensate for hypoxia. 
In these individuals, moderate changes in altitude may result in significant desaturation.

\section{Systemic blood pressure and left ventricular function}

After the initial peripheral vasodilation that occurs in direct response to hypoxia, blood pressure and systemic vascular resistance increase significantly as a consequence of sympathetic activation. Conflicting results exist if altitude exposure impairs left ventricular diastolic function and contributes to further increases in pulmonary arterial pressure $(15,24-29)$. Studies on adults with chronic heart failure (CHF) did not detect relevant cardiac deterioration at moderate altitude $(22,30,31)$, but cardiac changes have been observed in healthy individuals at extreme altitude and have been related to persistent exposure of the left ventricle to increased afterload, increased heart rate, as well as direct hypoxic metabolic changes $(1,13,32)$. On acute hypoxia, left ventricular stroke volume is maintained and cardiac output at rest is elevated due to the increased heart rate. On chronic hypoxia over a few days, cardiac output returns to normoxic baseline although heart rate remains elevated, indicating that stroke volume is decreased (22).

\section{Right atrial and ventricular function}

Acute exposure to high altitude and hypoxia is followed by an increase in pulmonary pressure and resistance due to the previously mentioned mechanism: hypoxia-induced pulmonary vasoconstriction, increased sympathetic activity and increased heart rate as well as potential left ventricular diastolic dysfunction. Consequently, the right ventricle (RV) is exposed to an increased afterload under hypoxic conditions. As shown recently in healthy individuals, global $\mathrm{RV}$ function is preserved but associated with a reduced passive filling and an increased contractile workload of the right atrium (33). RV failure at altitude is rare and mostly attributed to exercise-induced $\mathrm{PAH}$ or underlying subclinical disease $(15,22)$.

\section{Exercise and altitude exposure}

On exercise, these adaptive responses are additionally stressed and exercise performance is significantly reduced in comparison to that seen at sea level $(15,16,32,34-36)$. Exercise at high-altitude is associated with a relevant increase in pulmonary pressure and a decrease in maximal heart rate, maximal oxygen uptake and work load
$(12,20,22,36)$. For example, at $3,000 \mathrm{~m}$, maximum oxygen consumption is reduced to about $85 \%$ of its value at sea level. Pulmonary artery mean pressure doubles during exercise at $6,100 \mathrm{~m}$ altitude, and invasive measurements revealed a mean PAP of about $24 \pm 2 \mathrm{mmHg}$ at rest and $48 \pm 4 \mathrm{mmHg}$ at $200 \mathrm{~W}(15)$.

As a rule, above $1,500 \mathrm{~m}$ altitude, a $10 \%$ decrease in peak oxygen uptake $\left(\mathrm{VO}_{2}\right)$ is observed in healthy individuals for every additional 1,000 $\mathrm{m}$ of altitude gained $(37,38)$.

\section{Effect of hypoxia during overnight altitude exposure}

Physiologic responses during sleep on prolonged altitude exposure in children beyond infancy are similar to those seen in adults: at altitudes of about 3,500 m, healthy children resident at sea level experience periodic breathing and further oxygen desaturation during sleep $(10,39)$. This may have an impact on overnight excursions and has to be taken into consideration when planning long-term altitude exposure. At lower levels, for example during commercial airline travel, a pediatric study did not find a significant drop in saturation while sleeping (40).

\section{Repeated altitude exposure}

During repeated high-altitude exposure, there is little intraindividual variability in the magnitude of the cardiovascular response. Individuals with a history of previous acute mountain sickness are at risk of becoming symptomatic at repeated high-altitude exposure. As previously mentioned, in the altitude-naïve, the interindividual variability to altitude exposure is large (9). This has important impact on counselling: in the absence of a history of exposure, the prediction of well-being at high altitude is very difficult. Therefore, simulation of altitude exposure can be used to evaluate the individual response and risk to hypoxia.

\section{Simulation studies}

Most studies on cardiopulmonary response to altitude have been performed as simulation studies using either normobaric hypoxic or hypobaric hypoxic environments, ranging from a face mask with insufflation of hypoxic gas mixture, body plethysmography, or normobaric respective hypobaric chambers.

For patients with primary pulmonary disease, the "hypoxic challenge test" (HCT) has been introduced to 
identify individuals who may develop symptoms and may require supplemental in-flight oxygen. During a $20 \mathrm{~min}$ challenge on $15 \%$ oxygen at rest, peripheral saturation is recorded. Arbitrary cut-off levels of $\mathrm{SO}_{2}<85 \%$ in children $<1$ year and $<90 \%$ in those $\geq 1$ year of age have been chosen as indicators of the need for in-flight oxygen. The use of this HCT has to be questioned in children and adults with congenital heart disease and/or PAH $(5,41,42)$.

Obviously, HCTs with short-term hypoxia at rest may not reflect realistic exposure to hypoxia compared to a longdistance flight or mountain excursion. Therefore, study settings including longer exposure to hypoxia, as well as exercise, are of great interest to simulate altitude exposure. In addition, the results need to be verified in real-life settings, i.e., observational studies on individuals during air travel or mountain stays.

\section{Altitude exposure in PAH}

Healthy children and adolescents can compensate for altitude hypoxemia by increasing minute ventilation and cardiac output. Therefore, air travel and mountain stays are safe for most. Children and adolescents with PAH are likely to be more vulnerable to high-altitude environments: altitude-induced hypoxia may be more pronounced in PAH with a variable, difficult to predict rise in pulmonary artery pressure and resistance, resulting in profound hypoxemia at rest and during exercise. In addition, their compensatory response to altitude hypoxemia (increased minute ventilation, increased cardiac output) may be limited (20). In the absence of sufficient clinical studies and based on expert opinion, current guidelines recommend that adult patients with advanced PAH [WHO-Functional Class (FC) III and IV] should avoid exposure to altitudes $>1,500_{-}$ $2,000 \mathrm{~m}$, and they should use oxygen supplementation if exposed to altitudes around 1,500-2,000 $\mathrm{m}$ (Class of recommendation I, Level of evidence C) (ESC Guideline, 2018) $(1,43)$. During prolonged air travel, in-flight oxygen administration should be considered for patients in WHOFC III and IV and those with arterial blood oxygen pressure consistently $<60 \mathrm{mmHg}$. A flow rate of $2 \mathrm{~L} / \mathrm{min}$ is suggested to raise inspired oxygen pressure to values seen at sea level. If patients receive oxygen at sea level, oxygen supply should be doubled. Patients should be advised to travel with written information about their PAH and about how to contact local PAH clinics within close proximity to the final destination (43).

Recent Pediatric European Guidelines (44) recommend that pediatric patients with $\mathrm{PAH}$ should only fly on commercial airplanes in a stable and compensated condition (Class I, Level of evidence C). Due to the fact, that data on children with $\mathrm{PAH}$ exposed to altitude are lacking, the European Guidelines recommend that patients with advanced disease, systemic PAP and/or impaired ventricular function should use supplemental oxygen during the flight to minimise hypoxic vasoconstriction. Patient caregivers should contact the airline in advance regarding the availability of supplemental in-flight oxygen.

The American Guidelines briefly state, that during airplane travel, supplemental oxygen use is reasonable in pediatric patients with PAH (Class IIa, Level of evidence Bmoderate strength, moderate evidence) (45).

Data on the acute and prolonged effect of altitude exposure in PAH patients are scant. Therefore, it remains difficult to counsel PAH patients wishing to undergo mountain or air travel. Table 1 summarizes studies on altitude exposure in individuals with different type of PAH. Systematic studies on children with PAH exposed to cabin pressures or high altitude are lacking. However, data from adult trials cannot be easily transferred to the pediatric population, as PAH in childhood is seen in a wide variety of conditions, including not only idiopathic PAH (IPAH), but also $\mathrm{PAH}$ associated with $\mathrm{CHD}$ and the growing population of pulmonary hypertensive vascular diseases in single ventricle physiology (Fontan) (44). Furthermore, children with PAH may suffer from additional risk factors including restrictive parenchymal or extraparenchymal lung disease after operation, the combination of pre- and postcapillary $\mathrm{PAH}$, and complex syndromal disease (Table 2).

\section{Studies in adults with $\mathrm{PAH}$}

In adults with PAH WHO group I with a FC of I to III, challenge tests with normobaric hypoxia $\left(15 \% \mathrm{FiO}_{2}\right)$ have been performed with various duration (10-40 min at rest and with mild exercise (Table 1) $(19,46,49)$, demonstrating that PAH patients tolerate moderate hypoxia. In 14 adults with WHO FC II and III on vasodilatation, Seccombe et al. (19) documented a significant increase in sPAP on hypoxia and mild exercise (rise of sPAP determined by Doppler echocardiography from $56 \pm 14 \mathrm{mmHg}$ at baseline to $75 \pm 17 \mathrm{mmHg}$ on hypoxia and mild exercise). RV function remained unchanged during hypoxia. PAH patients desaturated more than controls and desaturation correlated with sPAP in hypoxia.

Two studies reported data from a real-life approach. 
Table 1 Studies on patients with PAH and altitude exposure

\begin{tabular}{|c|c|c|c|c|c|c|}
\hline Author (ref) & Patients & Functional class and therapy & Test & Altitude & $\begin{array}{l}\text { Cardiopulmonary } \\
\text { assessment }\end{array}$ & Results \\
\hline \multicolumn{7}{|c|}{ Pulmonary arterial hypertension (PAH) } \\
\hline Seccombe et al., 2017 (19) & $\begin{array}{l}\text { PAH WHO Group I, } 14 \text { adults vs. } \\
\text { control }\end{array}$ & WHO FC II and III; on vasodilation therapy & $\begin{array}{l}\text { Simulation with mild } \\
\text { exercise }\end{array}$ & $\begin{array}{l}\text { HCT } 20 \mathrm{~min}, 15.1 \% \mathrm{FiO}_{2} \\
\text { equivalent to } 2,400 \mathrm{~m} \text { asl; } \\
\text { exercise: walking }<3 \mathrm{~km} / \mathrm{h}\end{array}$ & $\begin{array}{l}\text { Echo, art. BGA; pulmonary } \\
\text { function test }\end{array}$ & $\begin{array}{l}\text { PAH patient tolerate moderate hypoxia. Significant increase of SPAP on hypoxia } \\
\text { and exercise. RV function remained unchanged during hypoxia. Desaturation } \\
\text { correlated with SPAP. PAH desaturated more than control. Mild increase of } \\
\text { symptoms of breathlessness in PAH }\end{array}$ \\
\hline Groth et al., 2018 (46) & PAH WHO I and IV, 28 adults & NYHA I-III; 5 on vasodilation & Simulation, no exercise & $\begin{array}{l}\mathrm{HCT} 10 \mathrm{~min} ; 16.0 \% \mathrm{FiO}_{2} \\
\text { hyperoxia } 10 \mathrm{~min}\end{array}$ & $\begin{array}{l}\text { Full hemodynamics right } \\
\text { heart cath, art. BGA }\end{array}$ & $\begin{array}{l}\text { Pulmonary vasoreactivity on hyperoxia correlated with changes of pulmonary } \\
\text { vasoreactivity under hypoxia }\end{array}$ \\
\hline Thamm et al., 2011 (47) & PAH, 179 adults & $\begin{array}{l}\text { NYHA II }(n=77) / I I I)(n=74) / I V(n=8) \text {; PAH specific } \\
\text { monotherapy 46\%; combination therapy 32\%; } \\
\text { home- } \mathrm{O}_{2} 32 \%\end{array}$ & $\begin{array}{l}\text { Real life approach, } \\
\text { questionnaire }\end{array}$ & Flights & Questionnaire & $\begin{array}{l}\text { 20/179 (11\%) had mild to moderate events. Functional class does not predict } \\
\text { symptoms during altitude exposure. Air travel is tolerated in patients with WHO } \\
\text { FC III and IV }\end{array}$ \\
\hline Roubinian et al., 2012 (48) & PAH WHO I, 34 adults & $\begin{array}{l}\text { FC I-IV, mainly II and III, on vasodilatation; } 16 \text { home- } \mathrm{O}_{2} \text {; } \\
1 / 3 \text { with prostacyclin infusion }\end{array}$ & $\begin{array}{l}\text { Prospective study with } \\
\text { real life approach }\end{array}$ & $\begin{array}{l}\text { Mean } 1,968 \mathrm{~m} \text { asl }(\max 2,621 \mathrm{~m}) \text {; } \\
\text { duration } 3.6 \mathrm{~h}(1.0-7.3 \mathrm{~h})\end{array}$ & $\mathrm{SpO}_{2}$ & $\begin{array}{l}\text { Resting } \mathrm{SpO}_{2} \text { at sea level is not a good predictor of in-flight desaturation. Higher } \\
\text { altitiude associated with lower } \mathrm{Spg}_{2} \text {, median drop of } \mathrm{SPO}_{2}-4.9 \%(2 \text { to }-15.8) \text {. } \\
\text { Desaturation }<85 \% \text { associated with flight duration and prior use of home } \mathrm{O}_{2} \text {. } \\
\text { Lowest saturation observed at ambulation. } 1 / 3 \text { had symptoms in-flight. } \mathrm{FC} \text { does } \\
\text { not predict symptoms during altitude exposure }\end{array}$ \\
\hline Burns et al., 2013 (49) & $\mathrm{PAH}, 36$ adults & $\begin{array}{l}\text { NYHA FC I-III, mainly II and III; on vasodilator; } \\
\text { all } \mathrm{SO}_{2}>90 \% \text { at sea level }\end{array}$ & $\begin{array}{l}\text { Simulation }+ \text { mini- } \\
\text { exercise }+ \text { compared } \\
\text { to real life approach }\end{array}$ & $\begin{array}{l}\mathrm{HCT} 30 \mathrm{~min} ; 15.1 \% \mathrm{FiO}_{2} 30 \\
\text { minutes }+10 \mathrm{~m} \text { walk compared } \\
\text { to previous flight history in } 14\end{array}$ & Cap. BGA, $\mathrm{SpO}_{2}$ & $\begin{array}{l}\text { Both HCT and FC assessment are unreliable to identify patients who may have } \\
\text { symptoms during flights. Failing an HCT is not a definitive predictor of subsequent } \\
\text { problems during air travel, but it does indicate the likelihood of developing } \\
\text { significant arterial hypoxemia during a flight }\end{array}$ \\
\hline \multicolumn{7}{|l|}{ Congenital heart disease (CHD) } \\
\hline Waldman et al., 1983 (50) & $\begin{array}{l}28 \text { children with CHD with PAH; } \\
\text { before and after surgery }\end{array}$ & & Simulation, no exercise & $\begin{array}{l}\mathrm{HCT} 10 \mathrm{~min} ; 15 \% \mathrm{FiO}_{2} ; 10 \mathrm{~min} \\
\text { hyperoxia }\end{array}$ & $\begin{array}{l}\text { Full invasive hemodynamics } \\
\text { on right and left heart cath }\end{array}$ & $\begin{array}{l}\text { Pulmonary vascular hyperreactivity can be induced by breathing } 15 \% \mathrm{FiO}_{2} . \\
\text { Pulmonary vascular resistance is reversible by } 100 \% \text { oxygen }\end{array}$ \\
\hline \multicolumn{7}{|l|}{ Eisenmenger's syndrome (ES) } \\
\hline Broberg, 2007 (51) & $\begin{array}{l}\text { Adults; } 53 \text { ES vs. } 48 \text { acyanotic } \\
\text { heart disease }\end{array}$ & 11/40 flyers NYHA III-IV & Real life approach & Survey & & $\begin{array}{l}\text { Air travel is tolerated in ES. Symptoms were associated with flight duration. } \\
\text { Cyanosis in ES is related to RL-shunt of unoxygenated blood. Tissue oxygen } \\
\text { delivery adapted by shift of the dissociation curve }\end{array}$ \\
\hline Harinck et al., 1996 (52) & $\begin{array}{l}12 \text { Pt with cyanotic CHD vs. } 27 \\
\text { control; age } 16-26 \text { yrs; ES, n=8 }\end{array}$ & Various; $\mathrm{SaO}_{2}$ at sea level $69-98 \%$ & Simulation and real life & $\begin{array}{l}\text { HCT } 1.5 \text { and } 7.0 \mathrm{hrs} \text { in hypobaric } \\
\text { chamber }(8,000 \mathrm{ft}=2,438 \mathrm{~m}) \\
\text { plus two flight a } 2.5 \mathrm{~h} \text {, maximal } \\
\text { altitude } 1,829 \mathrm{~m}\end{array}$ & Cap. BGA, $\mathrm{SpO}_{2}$ & $\begin{array}{l}\text { Drop in saturation during hypobaric hypoxia is comparable to real life decrease } \\
\text { during flight. Moderate reduction in capillary } \mathrm{pO}_{2} \text {, indicating that tissue oxygen } \\
\text { delivery adapted in patients }\end{array}$ \\
\hline \multicolumn{7}{|l|}{$\mathrm{CHF}$-congestive heart failure } \\
\hline Agostoni et al., 2000 (32) & $\begin{array}{l}38 \mathrm{CHF} \text { vs. } 14 \text { controls LVEF } \\
<40 \%, 25 \text { primary CMP; } 13 \\
\text { ischemic heart disease }\end{array}$ & $\begin{array}{l}\text { FC classified by exercise capacity: } 12 \text { normal }\left(\mathrm{VO}_{2 \text { paeak }}\right. \\
>20 \mathrm{~mL} / \mathrm{min} / \mathrm{kg}) ; 14 \text { diminished }(15-20 \mathrm{~mL} / \mathrm{min} / \mathrm{kg}) \\
15 \mathrm{markedly} \text { low }(<15 \mathrm{~mL} / \mathrm{min} / \mathrm{kg})\end{array}$ & Simulation + exercise & $\begin{array}{l}\text { HCT by mouth piece + maximal } \\
\text { exercise at sea level: } 1,000 \mathrm{~m} \text {; } \\
1,500 \mathrm{~m} ; 2,000 \mathrm{~m} ; 3,000 \mathrm{~m}\end{array}$ & $\mathrm{SaO}_{2}$, spiroergometry & $\begin{array}{l}\text { The relative reduction in work rate at simulated altitudes is greater in } \mathrm{CHF} \text { than in } \\
\text { controls. The maximum work rate at } 3,000 \mathrm{~m} \text { was reduced by } 32 \% \text { in } \mathrm{CDF} \text { with } \\
\text { markedly reduced exercise capacity. In patients with severe } \mathrm{CHF} \text {, the work of } \\
\text { breathing becomes a major component of total body } \mathrm{VO}_{2}\end{array}$ \\
\hline Hobkirk et al., 2013 (30) & $72 \mathrm{CHF}$ vs. 18 controls & LVEF <40\%; NYHA FC II 74\%; FC III 26\% & Simulation & $\mathrm{HCT} ; 15 \% \mathrm{FiO}_{2} ; 60 \mathrm{~min}$ & $\mathrm{SaO}_{2}$, echo & Moderate decrease in $\mathrm{SaO}_{2}$ and moderate increase in SPAP \\
\hline Damy et al., 2015 (53) & $\begin{array}{l}18 \text { Pt with CHF; } 7 \text { with PAH } \\
\text { (CHF+PAH); } 11 \text { without (CHF- } \\
\text { PAH) }\end{array}$ & LVEF $<40 \%$; NYHA FC II-III & $\begin{array}{l}\text { Simulation with cross } \\
\text { over sildenafil therapy } \\
\text { + exercise }\end{array}$ & HCT $15 \% \mathrm{FiO}_{2}+$ exercise & $\mathrm{SaO}_{2}$, echo & $\begin{array}{l}\text { In hypoxia, } \mathrm{CHF}+\mathrm{PAH} \text { had a more marked decrease in } \mathrm{SaO}_{2} \text {, and increase in PAP } \\
\text { at rest, and a markedly shorter exercise duration than } \mathrm{CHF}-\mathrm{PAH}\end{array}$ \\
\hline Ingle et al., 2012 (54) & 464 Pt with CHF & LVEF<40\%; NYHA FC II-III & Real life approach & Flights & Survey & $\begin{array}{l}35 \% \text { of CHF who travelled by air experienced health problems, mainly at the final } \\
\text { destination, going through security and on the aircraft }\end{array}$ \\
\hline
\end{tabular}

Table 1 (Continued) 
Table 1 (Continued)

\begin{tabular}{|c|c|c|c|c|c|}
\hline Author (ref) & Functional class and therapy & Test & Altitude & $\begin{array}{l}\text { Cardiopulmonary } \\
\text { assessment }\end{array}$ & Results \\
\hline \multicolumn{6}{|l|}{ Fontan } \\
\hline Garcia et al., 1999 (37) & $\begin{array}{l}\text { Fontan; } 11 \text { children and } \\
\text { adolescents; } 14.5 \pm 5.2 \text { yrs }\end{array}$ & Simulation + exercise & $\begin{array}{l}\text { Hypobaric chamber } 3,048 \mathrm{~m} \text { asl } \\
\text { + exercise }\end{array}$ & $\mathrm{SpO}_{2}, \mathrm{CO} \mathrm{VO}_{2}$, echo & $\begin{array}{l}\text { At altitude, Fontan patients desaturated from } 88.2 \% \pm 4.6 \% \text { at rest to } 80 \% \pm 6.3 \% \\
\text { with peak exercise. Cardiac output increased during submaximal exercise but } \\
\text { decreased at maximal exercise. Hypoxia was well tolerated }\end{array}$ \\
\hline Staempfli et al., 2016 (38) & $\begin{array}{l}\text { Fontan; } 16 \text { adult and } 14 \text { controls; } \\
27 \pm 7 \text { yrs; NYHA I-II }\end{array}$ & $\begin{array}{l}\text { Real life approach + } \\
\text { exercise }\end{array}$ & $\begin{array}{l}\text { Exercise testing at low altitude } \\
\text { and } 3,454 \mathrm{~m} ; 6 \text { hours altitude } \\
\text { exposure }\end{array}$ & $\begin{array}{l}\text { Pulmonary blood flow; } \\
\mathrm{SpO}_{2}, \mathrm{VO}_{2}\end{array}$ & $\begin{array}{l}\text { Fontan patients can adapt to hypoxic environments and remain asymptomatic. } \\
\text { Pulmonary blood flow increased despite an expected pulmonary hypoxic } \\
\text { vasoconstriction at altitude. Altitude exposure was well tolerated }\end{array}$ \\
\hline Takken et al., 2019 (55) & $\begin{array}{l}\text { Fontan; } 21 \text { children and adult vs. } \\
21 \text { control; } 19.8[8-37] \text { yrs; NYHA } \\
\text { I-II }\end{array}$ & Simulation + exercise & $\mathrm{HCT} ; 15 \% \mathrm{FiO}_{2}+$; exercise & $\mathrm{SpO}_{2}, \mathrm{VO}_{2}, \mathrm{CO}$ & $\begin{array}{l}\text { Cardiac output remains preserved at altitude. Pulmonary and hemodynamic } \\
\text { responses of high altitude exposure is comparable in Fontan patients and healthy } \\
\text { individuals }\end{array}$ \\
\hline Härtel et al., 2019 (56) & $\begin{array}{l}\text { Fontan; } 20 \text { children and adult } \\
\text { vs. } 20 \text { controls; NYHA I-II; } 18.4 \\
\text { [14-31] yrs }\end{array}$ & Simulation + exercise & $\begin{array}{l}\mathrm{HCT} ; 15.2 \% \mathrm{FiO}_{2} ; 2 \times 60 \mathrm{~min} ; \\
1 \text { hour submaximal exercise }\end{array}$ & $\mathrm{SpO}_{2}, \mathrm{SaO}_{2}, \mathrm{VO}_{2}$, echo & $\begin{array}{l}\text { Exposure equivalent to } 2,500 \mathrm{~m} \text { seems safe for Fontan patients. On hypoxia, } \\
1 \text { hour submaximal exercise was well tolerated }\end{array}$ \\
\hline
\end{tabular}

oxygen; $\mathrm{PAH}$, pulmonary arterial hypertension; $\mathrm{PAP}$, pulmonary arterial pressure; $\mathrm{pO}_{2}$, oxygen partial pressure; $\mathrm{SPAP}$, systolic $\mathrm{PAP}, \mathrm{RL}$-shunt, right-to-left shunt; $\mathrm{RV}$, right ventricle; $\mathrm{SpO}_{2}$, oxygen saturation by pulse oximeter; $\mathrm{SaO}_{2}$, arterial oxygen saturation, $\mathrm{VO}_{2}$, oxygen uptake. 
Table 2 Possible risk factors in pediatric PAH on altitude exposure $(2,57)$

Exaggerated pulmonary arterial pressure response to acute hypoxia

Dysfunction of the subpulmonary ventricle

Blunted hypoxic ventilatory response

Extraparenchymal restrictive lung disease (i.e., scoliosis, thoracic deformation)

Intraparenchymal restrictive lung disease

Combined right and left ventricular disease

Combined pre- and postcapillary PAH

Low training status

Reduced exercise performance, not able to increase cardiac output sufficiently

Exaggerated hypoxemia at exercise

Eisenmenger's syndrome with severe cyanosis

Chromosomal or syndromal disease

Unilateral absence of a pulmonary artery

$\mathrm{PAH}$, pulmonary hypertension.

In a prospective observational study on 34 adult PAH patients FC I-IV on vasodilation therapy or home oxygen, Roubinian 2012 (48) prospectively collected data throughout commercial flights. $\mathrm{SO}_{2}$ dropped by a median of $5 \%$. The most important factors associated with desaturation were flight duration and prior use of home oxygen. Lowest saturations were observed on ambulation. One third had symptoms during the flight, such as chest pressure, tightness, light-headedness, dyspnoea or palpitations, but symptoms were not related to the absolute fall in saturation. The authors found little association with clinical and functional measures of $\mathrm{PAH}$ : resting $\mathrm{SpO}_{2}$ was not a good predictor of symptoms during the flight. Using a questionnaire, in a cohort of 179 adult PAH patients FC I-IV, Thamm et al. (47) reported mild to moderate events (dyspnoea, peripheral edema, exhaustion) in $11 \%$ (20/179); $45 \%$ of the air travellers had PAH FC III and IV, representing the group of patients with the expected highest risk of developing symptoms during the flight. Of interest, there was only a small difference in adverse events observed between patients with FC II (9\%) and III or IV (13\%). The authors concluded, that patients with functional class III should not be excluded from altitude exposure.

Some experts recommend performing a hypoxia challenge test (HCT) to counsel patients with PAH. However, the contribution of such testing in preventing adverse events during air travel or altitude exposure has not been validated in pediatric PAH. In 14 adults with PAH, Burns et al. compared the results of an HCT with mild exercise to the previous flight history (49). Functional class was a poor indicator of the potential development of severe arterial hypoxemia or symptoms. In line with the previously mentioned studies $(19,46,47)$, a decrease in saturation below $90 \%$ under hypoxic challenge was not a good predictor of symptoms during air travel.

\section{Fontan circulation}

Palliative surgery in children with univentricular hearts is based on the creation of a Fontan circulation. The systemic venous return is connected to the pulmonary circuit in the absence of an interposed ventricle and pulmonary perfusion is solely dependent on passive pulmonary flow. The cardiac output in Fontan circulation is reliant on low pulmonary vascular resistance, the sufficient function of the downstream ventricle with a low atrial pressure and low transpulmonary gradient. Any significant impairment in pulmonary resistance or ventricular function results in an increase in the transpulmonary gradient, a decrease in cardiac preload and reduction in cardiac output (58). Accordingly, high altitude exposure with the anticipated hypoxic pulmonary vasoconstriction is expected to reduce pulmonary blood flow, compromise cardiac output and put individuals with Fontan circulation at risk. Therefore, 
current guidelines express concerns regarding safety of air travel or sport activities at high altitude in patients with Fontan circulation. Surprisingly, recent studies proved, that short-term exposure up to 6 hours and exercise at high altitude had no negative impact on Fontan patients and were tolerated well $(37,38,55,56)$.

In a case control study of 16 adults with stable Fontan circulation, Staempfli et al. (38) were able to prove that Fontan patients were capable of increasing pulmonary blood flow at rest and during submaximal exercise at an altitude of 3,454 $\mathrm{m}$ asl despite significant desaturation. Compared to baseline, at $540 \mathrm{~m}$ asl the relative change in $\mathrm{SpO}_{2}$, heart rate, minute ventilation and pulmonary blood flow did not differ between Fontan patients and healthy controls, keeping in mind that in general, baseline $\mathrm{SpO}_{2}$, pulmonary blood flow and exercise capacity are significantly lower in Fontan patients. The unexpected minimal response of the pulmonary vasculature to hypoxia-induced vasoconstriction may be related to chronic pulmonary vascular remodelling in Fontan patients. The authors conclude, that Fontan patients should not be discouraged from altitude exposure up to 6 hours a day, including leisure activities and air travel. Corresponding to this real-life study, HCTs including exercise studies in adolescents and adults $(37,55,56)$ confirmed that stable Fontan patients can adapt to hypoxic environments and remain asymptomatic regardless of the level of saturation. However, there is some evidence that long-term exposure to high altitude may have a negative impact on the Fontan circulation, involving other adaptive mechanisms (38).

\section{Cyanotic heart disease/Eisenmenger's syndrome (ES)}

Data about altitude exposure in cyanotic heart disease with or without ES have mainly been obtained in adolescents and adults $(51,52)$. In ES, longstanding intra- or extracardiac left-to-right shunts result in a rise in pulmonary resistance and an irreversible PAH with right-to-left shunt. Patients with ES might be at risk when flying due to the effects of profound hypoxia and hyperviscosity. Hypoxia at altitude may increase the pulmonary vascular resistance and worsen the right-to-left shunt. Two published studies were able to show, that cyanotic patients with ES were able to tolerate moderate to high altitude exposure up to $2,438 \mathrm{~m}$. In contrast to patients without shunt lesions, they were able to increase cardiac output via right-to-left shunt, and could maintain adequate systemic oxygen delivery due to the already elevated hematocrit and shift of the oxygen dissociation curve to the right (51). Changes in the alveolar oxygen concentration had only a modest effect on hypoxemia with a desaturation of $7.6 \%$ in patients $v s .6 .8 \%$ in controls during 6 hours simulation at 2,438 $\mathrm{m}$ (compared to baseline) (52). Mean oxygen partial pressure decreased by $5.4 \mathrm{mmHg}$ in patients. During two 2.5 -hour flights at altitudes of 1,829 and $1,767 \mathrm{~m}$, the drop in saturation and oxygen partial pressure was less than during simulation. Of interest, lactate levels were obtained and showed a significant increase during simulation, but not during real flight. In the study by Broberg et al. (51), patients with ES were compared with acyanotic patients and a 10-year record of 1,157 flights was evaluated. The authors reported no serious adverse effects on account of the additional hypoxia during flight. As a result, they suggested that commercial air travel is safe in patients with stable ES. To avoid paradoxical emboli, dehydration should be avoided, anticoagulation therapy discussed and moderate in-flight mobility emphasized.

\section{CHF}

The cardiovascular response at high altitude in CHF has been evaluated in adults $(30,32,53,54)$. The systolic PAP in patients with $\mathrm{CHF}$ and $\mathrm{PAH}(\mathrm{CHF}+\mathrm{PAH})$ increased significantly at rest as well as on exercise during hypoxia compared to $\mathrm{CHF}$ without $\mathrm{PAH}$ (mean sPAP of about 60 $\mathrm{mmHg}$ in $\mathrm{CHF}+\mathrm{PAH}$ vs. $43 \mathrm{mmHg}$ in CHF-PAH) (53). $\mathrm{CHF}+\mathrm{PAH}$ had a markedly shorter exercise duration. Of interest, pulmonary function in patients with severe CHF plays a significant role and the work of breathing on exercise under hypoxia may increase substantially in patients with severe CHF (32).

\section{Oxygen-supplementation and effect on byperoxia}

Testing of pulmonary vasoreactivity, i.e., pulmonary vascular response to hyperoxia, is a well-known assessment tool in patients with congenital heart disease. Oxygenenriched air reduces pulmonary vascular resistance in healthy individuals, as well as in patients with preserved pulmonary vasoreactivity (50). Recent trials indicate that breathing oxygen-enriched air increases exercise performance in healthy subjects and in PAH patients $(20,46)$. This is associated with a reduction in the ventilatory drive, allowing for more efficient ventilation and increased availability of oxygen to the end organs. In adults with 
PAH Type I, hyperoxia significantly decreased mean PAP by $4 \mathrm{mmHg}$ (range, 2-6 $\mathrm{mmHg}$ ) (46), without decreasing pulmonary vascular resistance. In the light of supplemental oxygen supply during altitude exposure, the question remains whether oxygen should be offered at the initiation of a flight, or at onset of desaturation or symptoms. Of interest, the increase in PAP induced by hypoxic pulmonary vasoconstriction cannot be rapidly and fully reversed with return to normoxia (7). Therefore, oxygen supplementation should be considered before the onset of acute pulmonary vasoconstriction.

\section{Recommendations}

General recommendations are summarized in Table 3. Individual counselling in patients with $\mathrm{PAH}$ with respect to altitude exposition is important. In patients in whom exercise tolerance is difficult to assess, or who are at high risk of hemodynamic deterioration, simulation under hypoxic conditions with moderate activity can be performed, in order to estimate the individual risk of high altitude conditions. If there is any doubt, oxygen supplementation during a flight should be recommended, or high risk patients should be advised not to fly. Regarding recommendations for neonates and infants, we refer to the papers of Samuels, Kohl and Barnett, Bossley and Balfour-
Lynn, and Israels et al. $(21,57,60,61)$.

In summary, patients with PAH may be at risk of developing clinically relevant events on altitude exposure. In patients with stable PAH, ES, heart failure with elevated pulmonary pressure, and Fontan circulation, air travel and mountain excursion at altitudes up to $3,000 \mathrm{~m}$ seem to be safe and well tolerated. Identifying those at risk, where compensatory mechanisms are failing, is challenging. Unfortunately, current measures of disease severity, including resting desaturation at sea level or during HCTs and functional class, do not accurately predict the onset of clinically relevant symptoms. At high altitude, exercise leads to further desaturation and a rise in pulmonary pressures, and therefore, it is reasonable to integrate moderate level exercise in fitness-to-fly or fitness-to-climb testing of patients. Further research is warranted to clarify the risk of altitude travel through implementation of comprehensive cardiac and pulmonary functional testing, including exercise under normo- and hypoxia, longer exposure to hypoxia including overnight stay, and the correlation with real-life data during flights or mountain stays. Based on these scientific data, the clinical relevance of hemodynamic parameters and the relevance of various degrees of desaturation depending on the type of PAH can be determined. This allows for specification of evidence-based guidelines, as well as the

Table 3 Summary of key points adapted from Shrikrishna et al., 2011 (59)

* Effects of altitude on the cardiovascular system

- At altitudes of 2,400-2,500 m, the partial pressure of oxygen falls to the equivalent of breathing of about $15 \% \mathrm{O}_{2}$ at sea level

- In healthy individuals, arterial oxygen tension falls to 53-64 mmHg, corresponding to SpO2 of 85-91\%, although when exercising or sleeping it may be lower. The pulmonary pressure rises immediately and remains elevated throughout altitude exposure

- In healthy individuals, exercise performance is significantly reduced in comparison to at sea level. During exercise, hypoxemia and pulmonary pressure are more pronounced. The individual response of pulmonary pressure on exercise is highly variable

- In patients with PAH, the exercise performance is already impaired in normoxia and even more so in hypoxic conditions. Patients with $\mathrm{PAH}$ desaturate more than healthy individuals, and may have a significant increase in pulmonary artery pressure

* Assessment before altitude exposure in pediatric pulmonary hypertension

- Physicians should consider the patient's previous experience during altitude exposure

- For flights: previous flight experience, flight duration, progress of disease since last exposure, acute illness

- For skiing or mountain breaks altitude of last exposure, duration, altitude of overnight sleep, amount of exercise, acute illness

* Selection of patients at risk of developing symptoms during acute altitude exposure

- Systematic studies on children with PAH exposed to cabin pressures or high altitude are lacking

- In adult patients with stable pulmonary hypertension, air travel is safe and well tolerated

Table 3 (Continued) 
Table 3 (Continued)

- Neither resting sea level $\mathrm{SO}_{2}$ nor resting $\mathrm{SO}_{2}$ during a hypoxic challenge test appear to predict the cardiovascular response or potential risks accurately

- The clinical relevance of hemodynamic changes and desaturations is dependent on the type of pediatric PAH (CHD with residual shunt, CHF, Fontan, idiopathic or hereditable)

- In adult patients with PAH functional class II-III, functional class does not predict the occurrence of symptoms during altitude exposure

- Comprehensive functional cardiac testing, including exercise testing in normoxia as well as hypoxia prior to altitude exposure, may uncover impaired functional reserve of the cardiovascular system; a systematic evaluation of simulation tests with real-life settings is mandatory

- Care should be optimised in patient groups at greatest risk, including

- Functional class III and IV

- Patients with significant symptoms at previous altitude exposure

- Dyspnoea, chest pain, confusion, syncope

- Comorbidity with pulmonary disease: severe obstructive disease (asthma) or restrictive disease (including chest wall disease)

- Risk of venous thromboembolism

- Pre-existing requirement for oxygen, long-term oxygen therapy

- Anemia

* Contraindications for altitude exposure including commercial air travel are: usual oxygen requirement at sea level at a flow rate exceeding $4 \mathrm{~L} / \mathrm{min}$, acute deterioration of pulmonary hypertension, acute infection, major hemoptysis

* Guidelines for patients

- Flight

- Contact the airline prior to travel concerning special needs (medical oxygen, special seat request)

- Avoid excess physical and mental stress and dehydration before, during and after flight including check in, transit and arrival

- Mountain travel

- Slow ascent, rest on arrival, consider lower altitude overnight stay

- Medication on air or mountain travel: continue with medication, vasodilators including sildenafil, bosentan, etc., should be carried in hand luggage and taken as scheduled

- Obtain advice on emergency plan for acute exacerbation.

- Obtain a doctor's letter if taking unusual medication or equipment, written information about PAH, advice on how to contact local $\mathrm{PAH}$ clinics close to the final destination

* Oxygen in-flight

- In-flight oxygen is prescribed at a rate of 2 or $4 \mathrm{~L} / \mathrm{min}$ via nasal cannulae and is usually supplied by the airline with advance booking

- Double the usual flow rate for long-term oxygen therapy patients

- Individuals with a history of supplemental oxygen should be evaluated for supplemental in-flight oxygen

* Risk of thromboembolic disease

- The risk of venous thromboembolic disease is greatest on flights lasting over eight hours

- Patients should be well hydrated and be advised to remain mobile during the flight

- High risk of thromboembolic disease: consider pre-flight prophylactic dose of low molecular weight heparin (cave hemoptysis) 
development of easy to apply and reliable tests to predict the potential risk of altitude exposure in the individual $(5,41,57,62)$.

\section{Acknowledgments}

We thank Ute Baur, Hilla Albus and Julian Härtel for their support; and Emma Raderschadt for editorial assistance.

Funding: The study of Härtel et al. (Thorac Cardiovasc Surg, 2019) was supported by the "KinderHerz-Innovationspreis NRW 2016."

\section{Footnote}

Provenance and Peer Review: This article was commissioned by the Guest Editors (Christian Apitz and Astrid Lammers) for the series "Pediatric Pulmonary Hypertension" published in Cardiovascular Diagnosis and Therapy. The article has undergone external peer review.

Peer Review File: Available at http://dx.doi.org/10.21037/ cdt-20-494

Conflicts of Interest: All authors have completed the ICMJE uniform disclosure form (available at http://dx.doi. org/10.21037/cdt-20-494). The series "Pediatric Pulmonary Hypertension" was commissioned by the editorial office without any funding or sponsorship. Dr. UH reports grants from Stiftung Kinderherz, Innovationspreis NRW, during the conduct of the study. Dr. JB reports financial support for lectures and being a consultant for ACTELION company. The authors have no other conflicts of interest to declare.

Ethical Statement: The authors are accountable for all aspects of the work in ensuring that questions related to the accuracy or integrity of any part of the work are appropriately investigated and resolved.

Open Access Statement: This is an Open Access article distributed in accordance with the Creative Commons Attribution-NonCommercial-NoDerivs 4.0 International License (CC BY-NC-ND 4.0), which permits the noncommercial replication and distribution of the article with the strict proviso that no changes or edits are made and the original work is properly cited (including links to both the formal publication through the relevant DOI and the license). See: https://creativecommons.org/licenses/by-nc-nd/4.0/.

\section{References}

1. Parati G, Agostoni P, Basnyat B, et al. Clinical recommendations for high altitude exposure of individuals with pre-existing cardiovascular conditions: A joint statement by the European Society of Cardiology, the Council on Hypertension of the European Society of Cardiology, the European Society of Hypertension, the International Society of Mountain Medicine, the Italian Society of Hypertension and the Italian Society of Mountain Medicine. Eur Heart J 2018;39:1546-54.

2. Rimoldi SF, Sartori C, Seiler C, et al. High-Altitude Exposure in Patients with Cardiovascular Disease: Risk Assessment and Practical Recommendations. Progress in Cardiovascular Diseases 2010;52:512-24.

3. Medical Guidelines for Airline Travel, 2nd ed. Aviat Space Environ Med 2003;74:A1-19.

4. Ahmedzai S, Balfour-Lynn IM, Bewick T, et al. Managing passengers with stable respiratory disease planning air travel: British Thoracic Society recommendations. Thorax 2011;66 Suppl 1:11-30.

5. Kobbernagel HE, Nielsen KG, Hanel B. Hypoxic challenge test applied to healthy children: influence of body positions and exertion on pulse oximetric saturation. Arch Dis Child 2013;98:602-6.

6. Talbot NP, Balanos GM, Dorrington KL, et al. Two temporal components within the human pulmonary vascular response to approximately $2 \mathrm{~h}$ of isocapnic hypoxia. J Appl Physiol (1985) 2005;98:1125-39.

7. Swenson ER. Hypoxic pulmonary vasoconstriction. High Alt Med Biol 2013;14:101-10.

8. Kriemler S, Jansen C, Linka A, et al. Higher pulmonary artery pressure in children than in adults upon fast ascent to high altitude. Eur Respir J 2008;32:664-9.

9. Allemann Y, Stuber T, de Marchi SF, et al. Pulmonary artery pressure and cardiac function in children and adolescents after rapid ascent to 3,450 m. Am J Physiol Heart Circ Physiol 2012;302:H2646-53.

10. Scrase E, Laverty A, Gavlak JC, et al. The Young Everest Study: effects of hypoxia at high altitude on cardiorespiratory function and general well-being in healthy children. Arch Dis Child 2009;94:621-6.

11. Lumb AB, Slinger P. Hypoxic pulmonary vasoconstriction: physiology and anesthetic implications. Anesthesiology 2015;122:932-46.

12. Naeije R, Huez S, Lamotte M, et al. Pulmonary artery pressure limits exercise capacity at high altitude. Eur 
Respir J 2010;36:1049-55.

13. Allemann $Y$, Rotter M, Hutter D, et al. Impact of acute hypoxic pulmonary hypertension on $\mathrm{LV}$ diastolic function in healthy mountaineers at high altitude. Am J Physiol Heart Circ Physiol 2004;286:H856-62.

14. Allemann Y, Sartori C, Lepori M, et al. Echocardiographic and invasive measurements of pulmonary artery pressure correlate closely at high altitude. Am J Physiol Heart Circ Physiol 2000;279:H2013-6.

15. Reeves JT, Groves BM, Sutton JR, et al. Operation Everest II: preservation of cardiac function at extreme altitude. J Appl Physiol (1985) 1987;63:531-9.

16. Groves BM, Reeves JT, Sutton JR, et al. Operation Everest II: elevated high-altitude pulmonary resistance unresponsive to oxygen. J Appl Physiol (1985) 1987;63:521-30.

17. Smith TG, Talbot NP, Chang RW, et al. Pulmonary artery pressure increases during commercial air travel in healthy passengers. Aviat Space Environ Med 2012;83:673-6.

18. Vaillancourt M, Chia P, Sarji S, et al. Autonomic nervous system involvement in pulmonary arterial hypertension. Respir Res 2017;18:201.

19. Seccombe LM, Chow V, Zhao W, et al. Right heart function during simulated altitude in patients with pulmonary arterial hypertension. Open Heart 2017;4:e000532.

20. Ulrich S, Schneider SR, Bloch KE. Effect of hypoxia and hyperoxia on exercise performance in healthy individuals and in patients with pulmonary hypertension: a systematic review. J Appl Physiol (1985) 2017;123:1657-70.

21. Samuels MP. The effects of flight and altitude. Arch Dis Child 2004;89:448-55.

22. Naeije R. Physiological Adaptation of the Cardiovascular System to High Altitude. Progress in Cardiovascular Diseases 2010;52:456-66.

23. Taylor AT. High-altitude illnesses: physiology, risk factors, prevention, and treatment. Rambam Maimonides Med J 2011;2:e0022.

24. Sareban M, Perz T, Macholz F, et al. Impairment of left atrial mechanics does not contribute to the reduction in stroke volume after active ascent to $4559 \mathrm{~m}$. Scand J Med Sci Sports 2019;29:223-31.

25. Stembridge M, Ainslie PN, Boulet LM, et al. The independent effects of hypovolaemia and pulmonary vasoconstriction on ventricular function and exercise capacity during acclimatisation to $3800 \mathrm{~m}$. J Physiol 2019;597:1059-72.

26. Stembridge M, Ainslie PN, Hughes MG, et al.
Impaired myocardial function does not explain reduced left ventricular filling and stroke volume at rest or during exercise at high altitude. J Appl Physiol (1985) 2015;119:1219-27.

27. Stembridge M, Ainslie PN, Shave R. Mechanisms underlying reductions in stroke volume at rest and during exercise at high altitude. Eur J Sport Sci 2016;16:577-84.

28. Bernheim AM, Kiencke S, Fischler M, et al. Acute changes in pulmonary artery pressures due to exercise and exposure to high altitude do not cause left ventricular diastolic dysfunction. Chest 2007;132:380-7.

29. Boos CJ, O'Hara JP, Mellor A, et al. A Four-Way Comparison of Cardiac Function with Normobaric Normoxia, Normobaric Hypoxia, Hypobaric Hypoxia and Genuine High Altitude. PLoS One 2016;11:e0152868.

30. Hobkirk JP, Damy T, Walters M, et al. Effects of reducing inspired oxygen concentration for one hour in patients with chronic heart failure: implications for air travel. Eur J Heart Fail 2013;15:505-10.

31. Smith D, Toff W, Joy M, et al. Fitness to fly for passengers with cardiovascular disease. Heart 2010;96:ii1-ii16.

32. Agostoni P, Cattadori G, Guazzi M, et al. Effects of simulated altitude-induced hypoxia on exercise capacity in patients with chronic heart failure. Am J Med 2000;109:450-5.

33. Sareban M, Perz T, Macholz F, et al. Preserved right ventricular function but increased right atrial contractile demand in altitude-induced pulmonary hypertension. Int J Cardiovasc Imaging 2020;36:1069-76.

34. Fukuda T, Maegawa T, Matsumoto A, et avl. Effects of acute hypoxia at moderate altitude on stroke volume and cardiac output during exercise. Int Heart J 2010;5 1:170-5.

35. Lewis GD, Bossone E, Naeije R, et al. Pulmonary vascular hemodynamic response to exercise in cardiopulmonary diseases. Circulation 2013;128:1470-9.

36. Huez S, Retailleau K, Unger P, et al. Right and left ventricular adaptation to hypoxia: a tissue Doppler imaging study. Am J Physiol Heart Circ Physiol 2005;289:H1391-8.

37. Garcia JA, McMinn SB, Zuckerman JH, et al. The role of the right ventricle during hypobaric hypoxic exercise: insights from patients after the Fontan operation. Med Sci Sports Exerc 1999;31:269-76.

38. Staempfli R, Schmid JP, Schenker S, et al. Cardiopulmonary adaptation to short-term high altitude exposure in adult Fontan patients. Heart 2016;102:1296-301.

39. Gavlak JC, Stocks J, Laverty A, et al. The Young Everest 
Study: preliminary report of changes in sleep and cerebral blood flow velocity during slow ascent to altitude in unacclimatised children. Arch Dis Child 2013;98:356-62.

40. Lee AP, Yamamoto LG, Relles NL. Commercial airline travel decreases oxygen saturation in children. Pediatr Emerg Care 2002;18:78-80.

41. Naqvi N, Doughty VL, Starling L, et al. Hypoxic Challenge Testing (Fitness to Fly) in children with complex congenital heart disease. Heart 2018;104:1333-8.

42. Files MD, Deen JF. Off we go into the wild blue yonder: preflight hypoxic testing in patients with congenital heart disease. Heart 2018;104:1313-4.

43. Galie N, Humbert M, Vachiery JL, et al. 2015 ESC/ERS Guidelines for the diagnosis and treatment of pulmonary hypertension: The Joint Task Force for the Diagnosis and Treatment of Pulmonary Hypertension of the European Society of Cardiology (ESC) and the European Respiratory Society (ERS): Endorsed by: Association for European Paediatric and Congenital Cardiology (AEPC), International Society for Heart and Lung Transplantation (ISHLT). Eur Respir J 2015;46:903-75.

44. Lammers AE, Apitz C, Zartner P, et al. Diagnostics, monitoring and outpatient care in children with suspected pulmonary hypertension/paediatric pulmonary hypertensive vascular disease. Expert consensus statement on the diagnosis and treatment of paediatric pulmonary hypertension. The European Paediatric Pulmonary Vascular Disease Network, endorsed by ISHLT and DGPK. Heart 2016;102:ii1-ii13.

45. Abman SH, Hansmann G, Archer SL, et al. Pediatric Pulmonary Hypertension: Guidelines From the American Heart Association and American Thoracic Society. Circulation 2015;132:2037-99.

46. Groth A, Saxer S, Bader PR, et al. Acute hemodynamic changes by breathing hypoxic and hyperoxic gas mixtures in pulmonary arterial and chronic thromboembolic pulmonary hypertension. Int J Cardiol 2018;270:262-7.

47. Thamm M, Voswinckel R, Tiede H, et al. Air travel can be safe and well tolerated in patients with clinically stable pulmonary hypertension. Pulm Circ 2011;1:239-43.

48. Roubinian N, Elliott CG, Barnett CF, et al. Effects of commercial air travel on patients with pulmonary hypertension air travel and pulmonary hypertension. Chest 2012;142:885-92.

49. Burns RM, Peacock AJ, Johnson MK, et al. Hypoxaemia in patients with pulmonary arterial hypertension during simulated air travel. Respir Med 2013;107:298-304.

50. Waldman JD, Lamberti JJ, Mathewson JW, et al. Congenital heart disease and pulmonary artery hypertension. I. Pulmonary vasoreactivity to $15 \%$ oxygen before and after surgery. J Am Coll Cardiol 1983;2:1158-64.

51. Broberg CS, Uebing A, Cuomo L, et al. Adult patients with Eisenmenger syndrome report flying safely on commercial airlines. Heart 2007;93:1599-603.

52. Harinck E, Hutter PA, Hoorntje TM, et al. Air travel and adults with cyanotic congenital heart disease. Circulation 1996;93:272-6.

53. Damy T, Hobkirk J, Walters M, et al. Development of a Human Model for the Study of Effects of Hypoxia, Exercise, and Sildenafil on Cardiac and Vascular Function in Chronic Heart Failure. J Cardiovasc Pharmacol 2015;66:229-38.

54. Ingle L, Hobkirk J, Damy T, et al. Experiences of air travel in patients with chronic heart failure. Int J Cardiol 2012;158:66-70.

55. Takken T, Evertse A, de Waard F, et al. Exercise responses in children and adults with a Fontan circulation at simulated altitude. Congenit Heart Dis 2019;14:1005-12.

56. Härtel JA, Müller N, Manunzio U, et al. Physical Exercise Is Safe for Fontan Patients in Hypoxia. Thorac Cardiovasc Surg 2019;67:DGPK-V1.

57. Israels J, Nagelkerke AF, Markhorst DG, et al. Fitness to fly in the paediatric population, how to assess and advice. Eur J Pediatr 2018;177:633-9.

58. Veldtman GR, Opotowsky AR, Wittekind SG, et al. Cardiovascular adaptation to the Fontan circulation. Congenit Heart Dis 2017;12:699-710.

59. Shrikrishna D, Coker RK. Managing passengers with stable respiratory disease planning air travel: British Thoracic Society recommendations. Thorax 2011;66:831-3.

60. Kohl SE, Barnett ED. What do we know about travel for children with special health care needs? A review of the 
literature. Travel Med Infect Dis 2020;34:101438.

61. Bossley C, Balfour-Lynn IM. Taking young children on aeroplanes: what are the risks? Arch Dis Child 2008;93:528-33.

Cite this article as: Herberg U, Knies R, Müller N, Breuer J. Altitude exposure in pediatric pulmonary hypertension—are we ready for (flight) recommendations? Cardiovasc Diagn Ther 2021;11(4):1122-1136. doi: 10.21037/cdt-20-494
62. Spoorenberg ME, Hulzebos EH, Takken T. Feasibility of Hypoxic Challenge Testing in Children and Adolescents with Congenital Heart and Lung Disease. Aerosp Med Hum Perform 2016;87:1004-9. 